\title{
Effects of sea horse (Hippocampus abdominalis)-derived protein hydrolysate on skeletal muscle development
}

\author{
Karthika Muthuramalingam ${ }^{1} \cdot$ Jun Ho Kim ${ }^{1} \cdot$ You Jin Jeon ${ }^{2} \cdot$ Sum Rho $^{3}$. \\ Young Mee Kim ${ }^{1}$ Moonjae Cho ${ }^{1,4}$
}

Received: 12 October 2017 / Accepted: 7 November 2017 / Published Online: 31 December 2017

(C) The Korean Society for Applied Biological Chemistry 2017

\begin{abstract}
Hippocampus abdominalis, the big belly sea horse, is widely known for its medicinal value in Chinese folk medicine. In this study, extract obtained by proteolytic degradation of this species was investigated for its effects on skeletal muscle development, both in vitro and in vivo. Muscle cell lines $\left(\mathrm{C}_{2} \mathrm{C}_{12}\right.$ and $\mathrm{L}_{6}$ ) treated with the bioactive peptide did not have any detrimental effects on the cell viability, which was above $80 \%$. Optical microscopy analysis on the morphology of the sea horse extract (SHE)-treated cells showed enhanced differentiating ability with myotube formation. Moreover, cells incubated with the hydrolysate displayed decreased proliferation rate, as recorded by the electric cell substrate impedance sensing system, thereby supporting enhanced differentiation. For a period of 12 weeks, mice models were fed with SHE and simultaneously subjected to treadmill exercise, which increased the expression of Myogenin, a key myogenic regulatory factor. In addition, there was an increase in the expression of AMPK- and Cytochrome $\mathrm{C}$, both of which are important in mitochondrial biogenesis. Thus, the SHE from Hippocampus abdominalis can be a promising candidate as protein supplement aiding muscle development.
\end{abstract}

Moonjae Cho ( $\triangle)$

E-mail: moonjcho@jejunu.ac.kr

${ }^{1}$ Department of Medicine, School of Medicine, Jeju National University, Jeju 63241, Republic of Korea

${ }^{2}$ Department of Marine Life Science, Jeju National University, Jeju 63243, Republic of Korea

${ }^{3}$ Haechunma Company Ltd, Jeju 63354, Republic of Korea

${ }^{4}$ Department of Medicine, School of Medicine, Institute of Medical Science Jeju National University, Jeju 63241, Republic of Korea

This is an Open Access article distributed under the terms of the Creative Commons Attribution Non-Commercial License (http://creativecommons. org/licenses/by-nc/3.0/) which permits unrestricted non-commercial use, distribution, and reproduction in any medium, provided the original work is properly cited.
Keywords Bioactive peptides · Mitochondrial biogenesis · Protein hydrolysate $\cdot$ Protein supplement $\cdot$ Sea horse

\section{Introduction}

The marine ecosystem is the Earth's largest aquatic system and is the habitat for marine organisms that are highly rich in medicinal value. Protein hydrolysates, a mixture of amino acids that are the product of protein hydrolysis obtained from marine species are gaining notable attention as therapeutic resources, as these products have high nutritional and pharmaceutical significance (Bordbar et al. 2011). The complex peptide molecules obtained from these hydrolysates have gained much interest in the field of nutritional clinical medicine when compared to the administration of intact proteins and free amino acids, due to their enhanced gastrointestinal absorption ability, high digestibility and supply of di- and tri-peptides. Common preparation methods for these hydrolysates include enzymatic hydrolysis, solvent extraction, and microbial fermentation (Vijaykrishnaraj and Prabhasankar 2015; Hou et al. 2017). Other common sources for protein hydrolysates includes maize, canola, egg white and yolk albumin, casein, whey, soybean, meat and pork among others (McCarthy et al. 2013; Lene Meinert et al. 2016).

Marine protein hydrolysates from fish exhibit several bioactive roles, such as anti-hypertension, anti-oxidant, immunomodulating, anti-appetizing, antimicrobial, anti-cholesterol and opioid antagonist (Imen et al. 2015; Vincenzo et al. 2016). In addition, administration of these short range peptides increases the plasma amino acid concentration and skeletal muscle protein anabolism thereby improving muscle hypertrophy and accelerating recovery of muscle cells making them suitable for sports nutrition (Manninen 2009). This is attributed to the ability of human skeletal muscle to oxidize externally supplemented amino acids such as isoleucine, valine, glutamate, asparagine, aspartate, alanine and leucine. 
Moreover, there is repression of muscle protein degradation and an increase in the catabolic activity on carbohydrates and lipids, to supply the energy required for muscle anabolism (Eva et al. 2006; Philips 2011).

The sea horse is a marine teleost fish that is a well-known ingredient in traditional Chinese medicines, due to its pharmacological significance (Feixia et al. 2016). Hippocampus abdominalis, the big belly sea horse, is one of the largest sea horse species, and has great medicinal value (Perera et al. 2016; Nalae et al. 2017). The majority of studies in this species focus on biochemical analyses, immunomodulating ability, radical scavenging, steroidogenic capacity and anti-fatigue property. However, scarce data exists regarding the biological and clinical characteristics of this sea horse and its role in muscle hypertrophy.

There is a strong correlation between myogenesis and the key transcription factors known as myogenic regulatory factors (MRFs) (Pacagnelli et al. 2016). Physical exercise increases protein synthesis and energy efficiency in the body, therefore analysis of the primary MRFs such as Myf5 and MyoD involved in cell proliferation and secondary MRFs such as Myogenin (Myo G) and Mrf4, responsible for myotube formation can be used to evaluate the effect of exercise on muscle growth (Valente et al. 2013). In addition, analysis of AMPK- expression is one of the primary indicators of ATP production due to energy expenditure by a process termed mitochondrial biogenesis (Richter and Ruderman 2009).

The present work aims to characterize the effects of administering marine protein hydrolysate obtained from the sea horse Hippocampus abdominalis on myogenic regulatory factors during physical training, both in vitro and in vivo to be applied to the field of sports nutrition.

\section{Materials and Methods}

\section{Cell line and culture medium}

Mouse myoblast cells $\left(\mathrm{C}_{2} \mathrm{C}_{12}\right.$ cells) and Rat myoblast cells $\left(\mathrm{L}_{6}\right.$ cells) were obtained from American Type Culture Collection (ATCC CRL-1772 and ATCC CRL-1458 respectively) and were cultured in Dulbecco's Modified Eagle Medium (Corning Cellgro, Manassas, VA, USA) supplemented with 10\% Fetal Bovine Serum (heat inactivated FBS; Corning Cellgro, Manassas, VA, USA) in a $95 \%$ humidified chamber with $5 \% \mathrm{CO}_{2}$ at $37{ }^{\circ} \mathrm{C}$. For cell differentiation studies, $2 \%$ Horse Serum Medium purchased (Sigma-Aldrich (Gyeonggi, Korea) was used.

\section{Preparation of $\boldsymbol{H}$. abdominalis protease enzymatic hydrolysates} Dried sea horse powder was provided by Haechunma Company Ltd., (Jeju, Korea). Distilled warer $(100 \mathrm{~mL})$ was added to $5 \mathrm{~g}$ of powder. The solution was subjected to hydrolysis using alcalase enzyme with a substrate to enzyme ratio of $100: 1$ at $37{ }^{\circ} \mathrm{C}$ for $24 \mathrm{~h}$. At the end of $24 \mathrm{~h}$, the $\mathrm{pH}$ of the solution was neutralized and the enzymes were inactivated by heating the solution to 100 ${ }^{\circ} \mathrm{C}$ for $10 \mathrm{~min}$ in a water bath. After centrifuging the solution for $20 \mathrm{~min}$ at $10,000 \mathrm{rpm}$, the soluble fraction was separated, freeze dried and stored at $-20{ }^{\circ} \mathrm{C}$ until further use (Kim et al. 2016).

\section{Cell viability assay}

The effect of the sea horse hydrolysate on the $\mathrm{C}_{2} \mathrm{C}_{12}$ viabilities was evaluated by the 3-(4,5-dimethylthiazol-2-yl)-2,5-diphenyltetrazolium bromide (MTT) assay, which determines viable cell count form active metabolism. Cells were treated with 0.05, 0.1, 0.2, 0.5 and $1 \mathrm{mg} / \mathrm{mL}$ hydrolysate for $24 \mathrm{~h}$. At the end of treatment, $10 \mu \mathrm{L}$ of MTT reagent $(5 \mathrm{mg} / \mathrm{mL}$ in PBS) (Sigma Aldrich, Gyeonggi, Korea) -CAS: 298-93-1) was added to each well and left undisturbed until purple color precipitate was clearly observed under microscope. To this, $150 \mu \mathrm{L}$ of dimethyl sulfoxide (DMSO) (Amresco, Solon, OH, USA) was added to each well and incubated for $30 \mathrm{~min}$. Optical density was then measured at 570 $\mathrm{nm}$.

\section{Cell proliferation assay with the electric cell substrate impedance sensing (ECIS) system}

Electric cell-substrate impedance sensing (ECIS) is a non-invasive biophysical approach for real time monitoring of cells in in-vitro conditions (Giaever and Keese 1984). This approach is based on the dielectric property of cells, which induces an increase in impedance as confluence of the cultured cells on the plate increases. $\mathrm{C}_{2} \mathrm{C}_{12}$ cells were seeded on electrode plates and after $24 \mathrm{~h}$ incubation, the cells were allowed to grown in $2 \%$ Horse serum (HS) medium containing hydrolysate concentrations of $0.05,0.5$ and $1 \mathrm{mg} / \mathrm{mL}$. The entire electrode array was placed in a plate holder connected to the ECIS system, and cell proliferation analysis was performed using the ECIS system software (Applied Biophysics, Troy, NY, USA) (Sculcek et al. 2014). The growth curve was plotted between cell proliferation percentage and time.

\section{Cell differentiation study}

The effect of hydrolysate on cell differentiation was studied by allowing the myoblast cell line $\mathrm{C}_{2} \mathrm{C}_{12}$ to grow in DMEM in which $10 \%$ FBS was replaced with $2 \%$ HS with $1 \mathrm{mg} / \mathrm{mL}$ of the hydrolysate. The plate was then incubated at $37{ }^{\circ} \mathrm{C}$ and $5 \% \mathrm{CO}_{2}$ and observed under inverted microscope Olympus CKX41 (Olympus Corporation, Tokyo, Japan) once a day for the formation of myotubes. The medium in the culture plate was changed every $24 \mathrm{~h}$.

In addition, cellular RNA was collected each day and analyzed by polymerase chain reaction (PCR) for the expression of transcription factors such as $\mathrm{MyoD}$ and $\mathrm{MyoG}$, which aid in myotube formation. PCR instrument was purchased from Hangzhou Bioer Technology Co. Ltd., Zhejiang, China. Medium was removed from the cell culture dish at the end of each day followed by washing twice with $1 \times$ Phosphate Buffer Saline (PBS). Trizol $(500 \mu \mathrm{L})$ was added to the washed cell culture dish 
Table 1 RT-PCR conditions (A) Master Mix composition and (B) Reaction Condition

(A)

\begin{tabular}{cc}
\hline \hline Reagents & Volume 1X $(\mu \mathrm{L})$ \\
\hline Reaction buffer $5 \mathrm{X}$ & 4 \\
$\mathrm{MgCl}_{2} 2.5 \mathrm{mM}$ & 6 \\
Reverse Transcriptase & 1 \\
dNTP & 4 \\
Test sample & 5 \\
(RNA $(2 \mu \mathrm{g})+$ DEPC + oligodT $(1 \mu \mathrm{L}))$ & 20 \\
Total & \\
\hline
\end{tabular}

\begin{tabular}{cc}
\hline & \\
\hline E) & Condition \\
\hline Annealing & $25^{\circ} \mathrm{C}$ for $5 \mathrm{~min}$ \\
Extension & $42^{\circ} \mathrm{C}$ for $2 \mathrm{~h}$ \\
Reverse transcriptase inactivation & $75^{\circ} \mathrm{C}$ for $10 \mathrm{~min}$ \\
Storage & $4{ }^{\circ} \mathrm{C}$ for $30 \mathrm{~min}$ \\
\hline
\end{tabular}

Table 2 PCR analysis of myogenic regulatory factors expressed in the $\mathrm{C}_{2} \mathrm{C}_{12}$ cells in-vitro after treatment with SHE. Primer sequence specifications

(A)

\begin{tabular}{cll}
\hline \hline \multicolumn{2}{c}{ Gene name } & \multicolumn{1}{c}{ Primer Sequence $\left(5^{\prime} \rightarrow 3^{\prime}\right)$} \\
\hline \multirow{2}{*}{ Myogenin } & Forward & GAA GCG CAG GCT CAA GAA AG \\
& Reverse & GTC TGG GAA GGC AAC AGA CA \\
\hline \multirow{2}{*}{ MyoD } & $\begin{array}{l}\text { Forward } \\
\text { Reverse }\end{array}$ & $\begin{array}{l}\text { CAT AGA CTT GAC AGG CCC CG } \\
\text { CAT TCA CTT TGC TCA GGC GG }\end{array}$ \\
\hline \multirow{2}{*}{ GAPDH } & Forward & TCAGATCCACGACGGACACA \\
& Reverse & CATCTTCCAGGAGCGAGACC \\
\hline
\end{tabular}

(B)

\begin{tabular}{|c|c|c|c|}
\hline \multicolumn{2}{|c|}{ Reagents } & \multicolumn{2}{|c|}{ Volume 1X $(\mu \mathrm{L})$} \\
\hline \multicolumn{2}{|c|}{ 10X buffer } & & 3 \\
\hline \multicolumn{2}{|c|}{$20 \mathrm{mM}$ dNTP } & & 0.3 \\
\hline \multicolumn{2}{|c|}{ Forward primer $(10 \mathrm{pmol})$} & & 0.5 \\
\hline \multicolumn{2}{|c|}{ Reverse primer (10 pmol) } & & 0.5 \\
\hline \multicolumn{2}{|c|}{ Polymerase } & & 0.1 \\
\hline \multicolumn{2}{|c|}{ DNA concentration (from RT-PCR) } & & $\mu \mathrm{g}$ \\
\hline \multicolumn{2}{|c|}{ Distilled water } & & pto $30 \mu \mathrm{L}$ \\
\hline \multicolumn{2}{|c|}{ Total } & & 30 \\
\hline \multicolumn{4}{|l|}{ (C) } \\
\hline \multirow{2}{*}{ Experimental Steps } & \multicolumn{3}{|c|}{ Experimental Conditions } \\
\hline & Myogenin & MyoD & GAPDH \\
\hline Pre-Denaturation & \multicolumn{3}{|c|}{$95^{\circ} \mathrm{C}$ for $5 \mathrm{~min}$} \\
\hline Denaturation & \multicolumn{3}{|c|}{$95^{\circ} \mathrm{C}$ for $45 \mathrm{~s}$} \\
\hline Annealing & \multirow{2}{*}{$59^{\circ} \mathrm{C}$ for $55 \mathrm{~s}$} & \multicolumn{2}{|c|}{$62{ }^{\circ} \mathrm{C}$ for $55 \mathrm{~s} 57.5^{\circ} \mathrm{C}$ for 55} \\
\hline Extension & & \multicolumn{2}{|c|}{$72{ }^{\circ} \mathrm{C}$ for $1 \mathrm{~min}$} \\
\hline Final Elongation & \multicolumn{3}{|c|}{$72{ }^{\circ} \mathrm{C}$ for $2 \mathrm{~min}$} \\
\hline PCR Cycles & 35 & 45 & 35 \\
\hline Storage & \multicolumn{3}{|c|}{$4{ }^{\circ} \mathrm{C}$ for $30 \mathrm{~min}$} \\
\hline
\end{tabular}

and incubated at $4{ }^{\circ} \mathrm{C}$ for 20 min under shaking conditions, then collected from the dish with a cell scrapper. RNA was collected by chloroform-isopropanol extraction, and purity was assessed by DU series 730 UV/Visible spectrophotometer (Beckman Coulter, Inc. Brea, CA, USA). Complementary DNA (cDNA) was synthesized with reverse transcriptase enzyme (Promega, Madison, WI, USA) from the RNA by reverse transcriptase PCR (RT-PCR) (Table 1). PCR was performed on the synthesized cDNA using FIREPol DNA polymerase (Solis Biodyne, Estonia, Northern Europe) to analyze the expression of myogenic regulatorys as MyoG and MyoD and the loading control GAPDH. PCR conditions and primer sequences are provided in Table 2. The Table 2 provides a detail description on the PCR conditions and the sequence of the forward and reverse primers that are designed for MyoG, MyoD and GAPDH. The designed primer sequences were ordered and purchased from Genotech, Daejoen, Republic of Korea. And the PCR instrument was purchased from Hangzhoue Bioer Technology Co. Ltd., Zhejiang, China.

\section{In-vivo study}

The effect of Hippocampus protein hydrolysate on muscle development was studied in-vivo using ICR mice (about 5 weeks old) purchased from Orient Bio (Orient Bio Inc., Seongnam, Gyeonggi, Korea). Animals were housed at room temperature $\left(23 \pm 2{ }^{\circ} \mathrm{C}\right)$ with constant humidity $(55 \pm 15 \%)$ on a $12 \mathrm{~h}$ light $/ 12 \mathrm{~h}$ dark cycle, with free access to food and water for one week to adapt the laboratory environment. After 7 days, the mice were randomly divided into 2 group: Exercise and Non-exercise. Further, each of these groups are divided into three categories: control group (administered PBS only), test group 1 (administered Sea Horse Extract (SHE) $50 \mathrm{mg} / \mathrm{kg}$ ) and test group 2 (administered Sea Horse Extract (SHE) $200 \mathrm{mg} / \mathrm{kg}$ ) for analysis of the effect of protein hydrolysate on muscle development. The mice were fed with PBS and SHE through oral route of administration. Initially the groups were fed with the hydrolysate or control for one week followed by three weeks of treadmill training. From weeks 5-12, the mice were subjected to treadmill exercise at $20 \mathrm{~meters} / \mathrm{min}$ for 30 minutes once a week.

In order to study the effect of SHE together with exercise on aged group, two groups of mice (about 24 weeks old), each containing $n=4$ were used. With the same housing conditions, the aged group mice were subjected to treadmilling at a speed of 15 $\mathrm{m} / \mathrm{min}$ for $10 \mathrm{~min}$ once a week with SHE of $50 \mathrm{mg} / \mathrm{Kg}$. At the end of 3 months, hind limb tissues were taken from each group, followed by evaluation of the protein expression responsible for metabolic adaptation of the muscle cells under exercise and protein supplementation by western blotting was done.

\section{Western blot analysis}

Protein was extracted from the isolated hind limb tissues with T- 
per buffer (Thermo Scientific, Rockford, IL, USA). To $0.1 \mathrm{~g}$ tissue, $600 \mu \mathrm{L}$ of buffer was added and the tissue was homogenized thoroughly. The homogenate was centrifuged for $15 \mathrm{~min}$ at 14,000 $\mathrm{rpm}$ at $4{ }^{\circ} \mathrm{C}$ and the supernatant was carefelly collected to avoid contamination with fat content. Protein concentration was measured by BCA assay (Pierce Biotechnology, Rockford, IL, USA). The total protein concentration in the lysates was normalized to $20 \mu \mathrm{g}$ per lane and proteins were separated on a 10-12\% sodium dodecyl sulfate (SDS) polyacrylamide electrophoresis (SDS-PAGE) by loading equi-volume $(18 \mu \mathrm{L})$ of total protein in the gel. SDS was purchased from Biosesang, Gyeonggi, Korea. Proteins separated by SDS-PAGE were transferred to nitrocellulose blotting membrane (GE Healthcare, Life Science, German, UK) for 90 minutes at 250 $\mathrm{mA}$ followed by blocking with 5\% nonfat dry milk dissolved in of tris-buffered saline (TBS) and Polysorbate 20 (Tween 20) (TTBS) at 4 for overnight. Membranes were incubated with the following primary antibodies: MyoD (1:200), MyoG (1:500), AMPK- $\alpha$ (1:1000), UCP-3 (1:1000), Cyt C (1:1000), AKT $(1: 1000)$, mTOR $(1: 1000)$ and $\beta$-actin $(1: 1000)$ as the loading control. All primary antibodies were purchased from Santa Cruz Biotechnology (Santa Cruz, CA, Santa Cruz, USA). After incubation with the primary antibody, membranes were washed with $1 \mathrm{X}$ TTBS followed by $1 \mathrm{~h}$ incubation with secondary antibody raised against corresponding primary antibody. The concentration of the secondary antibodies is as follows: Rabbit $(1: 20,000)$, Mouse $(1: 20,000)$ and Goat $(1: 40,000)$. Blots were washed and then developed using an enhanced chemiluminescence ECL kit (LPS solution, Daejeon, Korea). Bands were quantified using ImageJ software (https://imagej.nih.gov/ij/).

\section{Statistical Analysis}

All data herein are expressed as mean $\pm \mathrm{SD}$. The quantified data of the bands obtained through PCR and western blotting techniques using ImageJ software were entered into a Microsoft Excel spreadsheet. The significant difference between the expression of the proteins from all the mice groups (Control, SHE50 $\mathrm{mg} / \mathrm{Kg}$ and SHE200 $\mathrm{mg} / \mathrm{Kg}$ of each exercise and nonexercise batch) were evaluated using independent $t$-test analysis with cut-off significance less than 0.05 .

\section{Results/Discussion}

The effect of protein hydrolysate on myoblast viability was evaluated using the MTT assay with two different cell lines- $\mathrm{C}_{2} \mathrm{C}_{12}$ (mouse myoblast cells) and $\mathrm{L}_{6}$ (rat myoblast cells). In all cases, the cell viability was above $80 \% .1 \mathrm{mg} / \mathrm{mL}$ of the protein hydrolysate had the most significant effect on the $\mathrm{C}_{2} \mathrm{C}_{12}$ cell viability followed by $0.5 \mathrm{mg} / \mathrm{mL}$ as seen from the Fig. 1 . Concentrations between 0.05 $0.2 \mathrm{mg} / \mathrm{mL}$ hydrolysate had a slightly lower cell viability compared to the untreated $\mathrm{C}_{2} \mathrm{C}_{12}$ cell lines; whereas $\mathrm{L}_{6}$ cells treated with $0.05-1 \mathrm{mg} / \mathrm{mL}$ of the protein hydrolysate has lower viability than the untreated $\mathrm{L}_{6}$ control group thus making them less compatible with the SHE in terms of cell growth. The decrease in the viability might be attributed to slower cellular proliferation in the presence of these hydrolysates.

The effect of SHE on the differentiation of muscle cells was also evaluated and is shown in Fig. 2. Cells were cultured with $2 \%$ HS in DMEM and the medium was changed every $24 \mathrm{~h}$. The impedance-based analysis on the proliferation of anchorage dependent myoblast cells under the influence of different concentrations of SHE hydrolysate and differentiation medium indicated that $1 \mathrm{mg} / \mathrm{mL}$ of SHE hydrolysate significantly slowed proliferation and differentiation of the muscle cells. Thus, further experiments were conducted to analyze the morphology of the differentiating muscle cells in-vitro under the influence of SHE hydrolysate at a concentration of $1 \mathrm{mg} / \mathrm{mL}$.

Differentiation of myoblasts begins after 5 days, when the

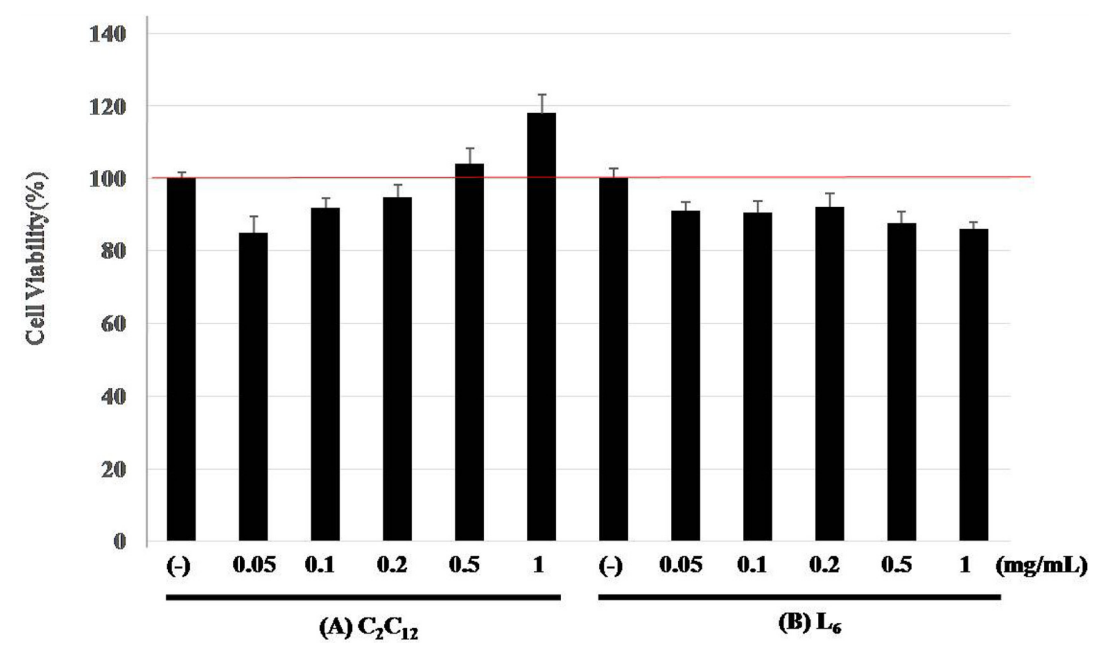

Fig. 1 Cell Viability analysis using MTT assay on the effect of the sea horse extract on two different cell lines. $(A) \mathrm{C}_{2} \mathrm{C}_{12}$ and (B) $\mathrm{L}_{6}$. Cells were treated with various concentrations of the protein hydrolysate for $24 \mathrm{~h}$ followed by incubation with MTT reagent. By solubilizing the formazan with DMSO, $\mathrm{OD}_{570 \mathrm{~nm}}$ was measured (where $\mathrm{n}$, the number of replicates $=6$ ) and the results were plotted 


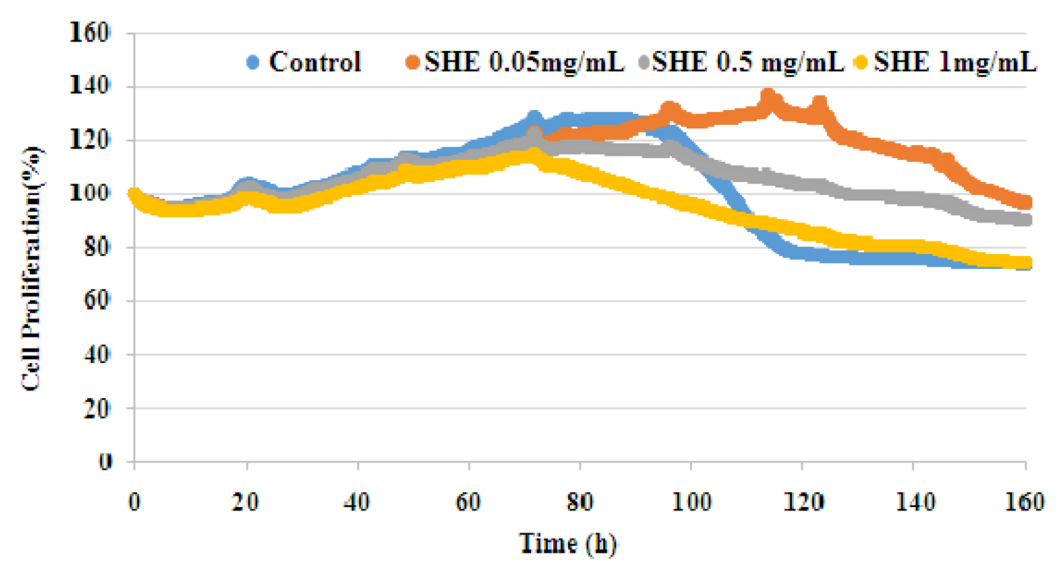

Fig. 2 Dose dependent effect of sea horse derived protein hydrolysate on proliferation resistance of $\mathrm{C}_{2} \mathrm{C}_{12}$ cells. Cells grown on an electrode array in the presence of $2 \%$ horse serum medium were subjected to electric cell substrate impedance sensing (ECIS) system, to study the proliferative ability of the cells under the influence of various concentrations of SHE hydrolysate. The results were plotted with proliferation $\%$ versus time

(A)

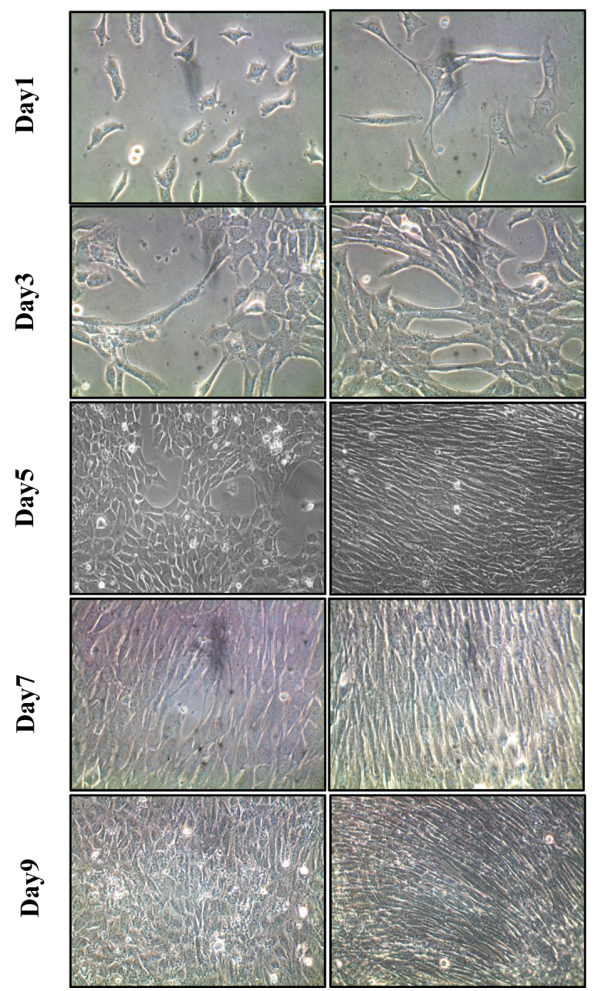

(B)

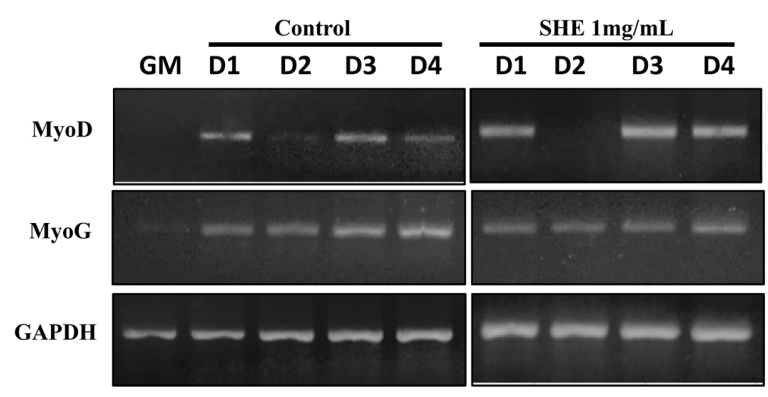

(C)

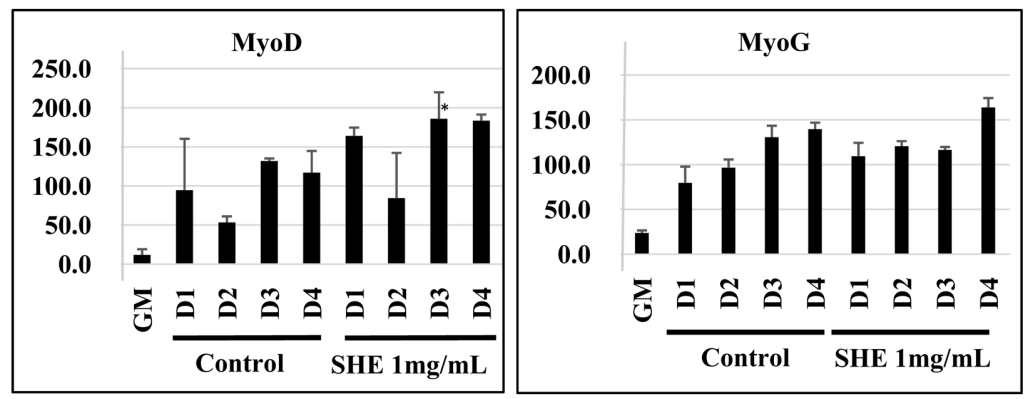

Fig. 3 Effect of SHE on differentiation of $\mathrm{C}_{2} \mathrm{C}_{12}$ cell lines on consecutive days of SHE treatment. (A) Morphology analysis using optical microscope after culturing the cells in $2 \%$ horse serum medium containing $1 \mathrm{mg} / \mathrm{mL}$ SHE (Day 1\&3: 100X magnification; Day 5,7\&9: 200X magnification). (B) RNA expression of myogenic regulatory factors (MRFs) using PCR. Cells were collected every day and RNA was extracted using Trizol. (C) Graph indicating the relative expression of MRFs with respect to the loading control GAPDH. The bands from the gel electrophoresis of the PCR products were analyzed using ImageJ software and the graph was plotted. The results are presented as mean \pm SD where the significance of the result is $p<0.05$ compared to the control

singly nucleated myoblast cells elongate and fuses with each other to form multinucleated myotubes in a process termed myogenesis (Teng et al. 2015). From the Fig. 3A, it is observed that a well differentiated muscle cell milieu was observed on day 9. Fig. 3B and $3 \mathrm{C}$ shows the analysis of the mRNA expression of myogenic regulatory factors from the control and SHE administered test group on the corresponding days indicating an increase in the level of MyoD, a primary regulatory factor responsible for directing proliferating myogenic satellite cells towards a myogenic lineage, and Myogenin, a secondary regulatory factor controlling 
(A)

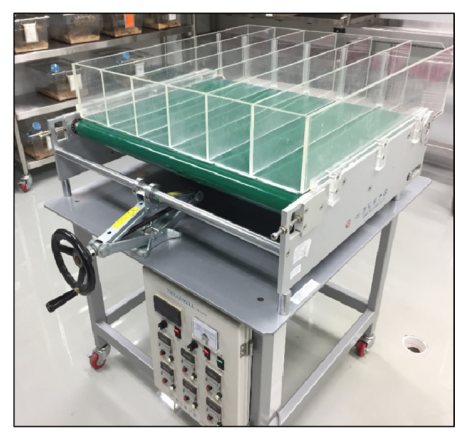

(B)

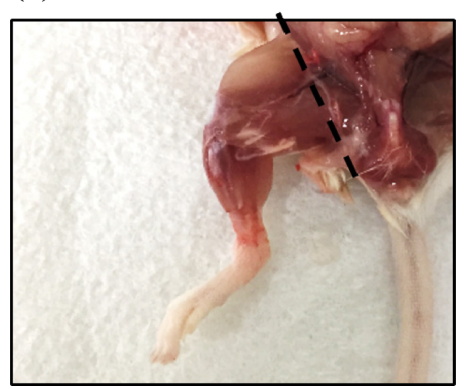

Fig. 4 Effect of $50 \mathrm{mg} / \mathrm{Kg}$ SHE on ICR mice in-vivo after exercise. (A) The treadmill running exercise machine (B). Area of skeletal muscle tissue excised from the animal for further analysis

differentiation leading to the formation of myofibers. The increase in the transcription of both $\mathrm{MyoD}$ and Myogenin plays a role in promoting regeneration of muscle fibers (Borselli et al. 2010). Thus the ECIS result was consistent with the morphology analysis of the cultured cells under optical microscopy along with evaluation of mRNA expression of the transcriptional markers of proliferation and differentiation.

The effect of SHE hydrolysate was also evaluated in-vivo in mice. Fig. 4A shows the treadmill machine used in the study. After 10 weeks of treadmill exercise, muscle tissue from the hind limb (given in Fig. 4B) of both the groups was collected and their protein extracts were analyzed for the effect of hydrolysate and exercise on muscle development. Western blot analysis for the proteins extracted from muscle tissue given in Figs. 5A, B, C corresponds to the young mice non-exercise group, young miceexercise group and old mice-exercise group respectively.

Dietary supplementation of protein along with exercise has been expected to impose positive impact on muscle remodeling by promoting muscle hypertrophy (Schoenfeld et al. 2013). Proteins extracted from the hind limb muscle tissue of the exercise and non-exercise mice groups were subjected to western blot experiment and analyzed for the protein factors involved in adaptive response towards the treadmill aerobic exercise.

The efficiency of the administered SHE together with the treadmilling in inducing myofibre maturation and muscle development is analysed by studying the expression of myogenic regulatory factors, MyoD and MyoG. MyoD, a muscle cell proliferation marker is responsible for inducing the expression of MyoG, which in turn results in well differentiated and matured muscle myofibers. An increased expression is observed with both the MyoD and MyoG proteins in the SHE administered exercise group than their corresponding non-exercise and control group.

Increase in expression of the two protein kinases -AKT and mTOR- which contributes to the maintenance of body muscle, is observed in the SHE treated-exercise mice group when comparing the SHE treated non-exercise mice group and their corresponding control to which SHE is not administered, in both the groups. It is seen from the literatures (Fernandes et al. 2012) that, the activation and stimulation of $\mathrm{mTOR}$ results as a consequence of its upstream signalling pathway PI3K/AKT/mTOR. Muscle contraction and cellular stress experienced during the treadmill process stimulates the AKT signalling pathway. Upon stimulation, AKT, a regulator of glucose homeostatis, phosphorylates mTOR thereby increasing muscle protein synthesis and muscle hypertrophy, as a result of which increase in muscle mass is expected. Further, Phosphorylated AKT is said to induce lysosomal degradation of SIRT1 by translocating it to the cytosolic region from the nucleus, by which antioxidant property of the cell is enhanced (Raja et al. 2017). Previous reports states that, AKT, in addition to mTOR, phosphorylates wide range of proteins that includes FOXO. The phosphorylated FOXO exits the nucleus and fails to activate a major E3 ligase, atrogin-1, thus protecting the muscle protein from degradation (Paul et al. 2016). Both the increase in the synthesis and decrease in degradation of the muscle protein is said to enhance the myofibrilar protein content and muscle mass.

Undergoing physical activities/exercises tends to develop oxidative stress in the muscle regions. In addition, there creates a ATP deprivation in the cells with increase in AMP:ATP ratio. All these events lead to activation of AMPK, a energy sensor of the body, which upon phosphorylation restores the ATP level by phosphorylating peroxisome proliferator activated receptor $\gamma$-coactivator $1 \alpha$ (PGC-1 $\alpha)$, a crucial regulator of mitochondrial biogenesis (Wengong et al. 2003; Collu-Marchese et al. 2015; Guadalupe-Grau et al. 2017). Activated PGC-1 allows mitochondria to get adapted to the stress condition imposed by increased energy expenditure, as observed in exercise, thereby maintaining them in functional state. Further, activated AMPK increases catabolic fatty acid oxidation and glucose uptake for poising the astrayed energy balance, besides downregulating the anabolic processes such as fatty acid synthesis and gluconeogenesis, a process in which glucose is generated, thereby increasing ATP generation and decreasing ATP consumption respectively.

Another mitochondrial biomarker, Cytochrome C (Cyt C) which quantifies the mitochondrial content and the mitochondrial DNA (mtDNA) is said to increase 2 to 3 fold during exercise (Holloszy 1967; Terjung et al. 1973). Herein, Cyt C expression in the SHE administered exercise group is higher that the corresponding control in the same group, indicating that protein supplementation together with the aerobic treadmilling has a 
(A)
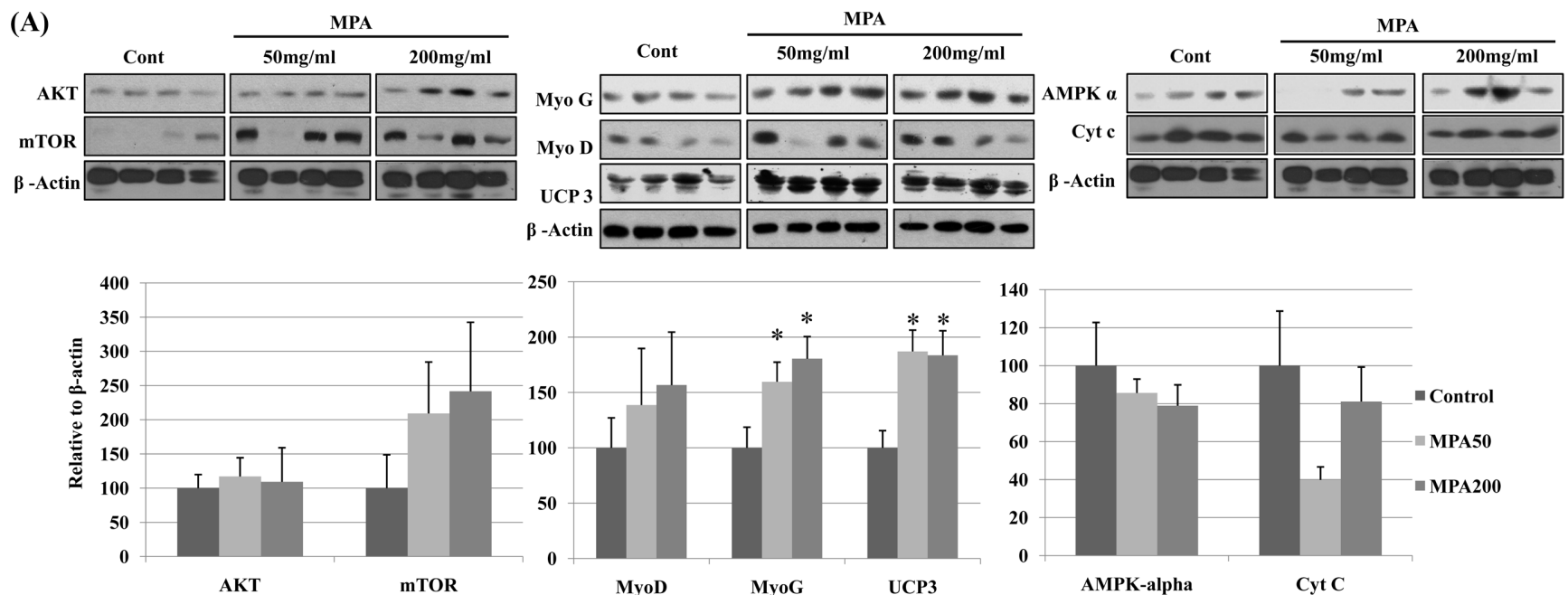

(B)
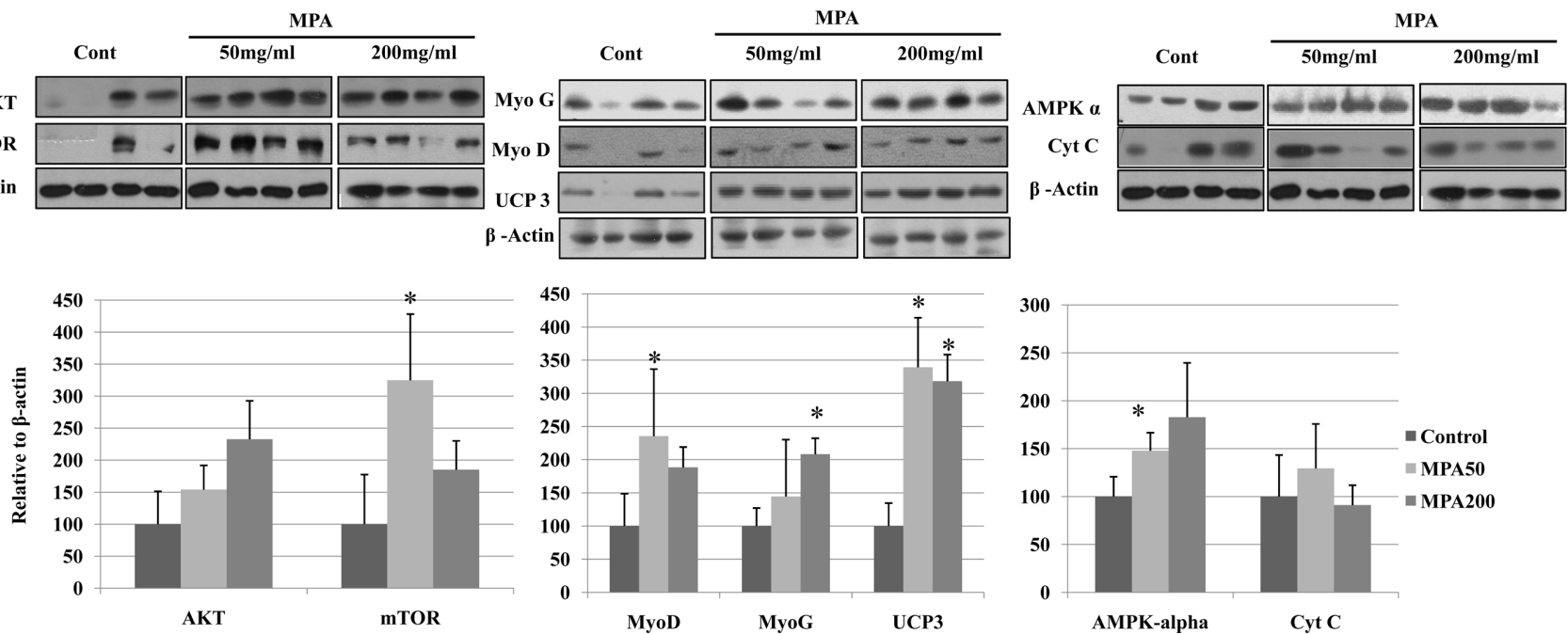

(C)
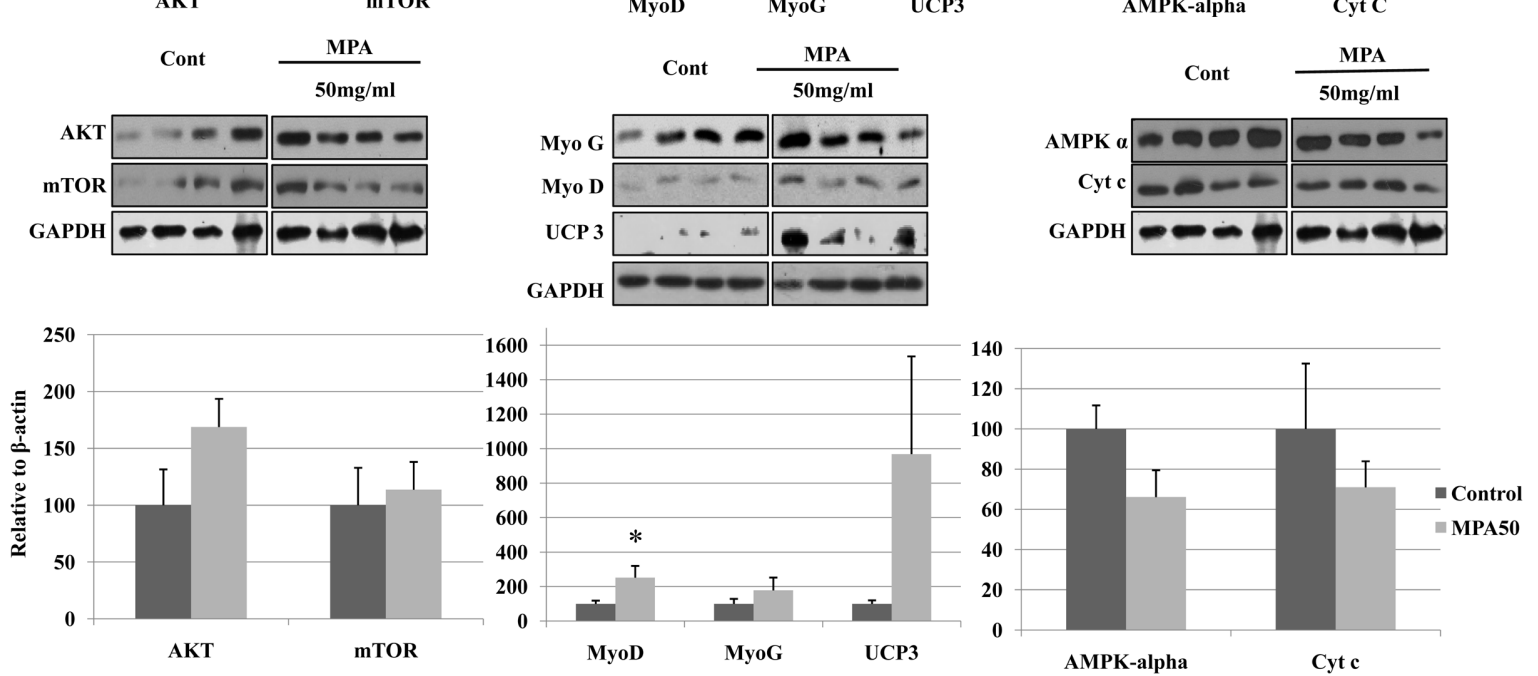

Fig. 5 Western blots and quantification graph for the proteins extracted from hind limb muscle of the mice in (A) Young mice non-exercise group (B) Young mice-exercise group (C) Old mice-exercise group. Proteins were extracted from the excised muscle tissues and are separated by performing SDS-PAGE. Primary and secondary antibody treatments were done against the factors associated with mitochondrial biogenesis and the proteins were detected using ECL solution. The bands were analyzed with ImageJ software and the data are plotted as mean \pm Standard error. $p$-value $<0.05$ (vs. Control) are considered statistically significant and are marked using * in the graph 
synergistic effect on mitochondrial biogenesis. This increased expression level of the mitochondrial marker supports the fact that PGC-1 $\alpha$, a downstream signalling molecule in the AMPK- $\alpha$ activation pathway has induced the mitochondrial biogenesis.

Nutrient depletion is said to increase the expression level of SIRT-1, a NAD ${ }^{+}$dependant deacetylase protein, thereby reducing muscle atrophy under energy expenditure/starvation (Gao et al. 2014). In the present study, both the SHE administered mice groups -exercise and non-exercise- showed lower SIRT-1 expression level than their respective control groups, indicating that the protein supplement provides enough nutrients to the muscle tissue, thereby blocking them towards entering nutrition deprivation state (Data not provided in the figure).

Increased expression of UCP3, a mitochondrial anion carrier protein, is observed in the exercise group than the non-exercise group and their corresponding control groups, which accounts for lowering the mitochondrial membrane potential together with reducing the stress imposed by overload of fatty acid in the muscle cells, thereby overcoming the dreadful effects of ROS accumulation (Patrick et al. 2006; Busiello et al. 2015). The primary role of UCP3 in skeletal muscle is to protect the mitochondria by making them metabolically adapt to the stress induced during exercise, thereby supporting ATP synthesize and energy partitioning (Miranda and Joris 2008).

Aging results in muscle atrophy and decrease in muscle strength as a result of reduction in the number and size of the muscle fibers and loss of muscle motors (Keller and Engelhardt 2013). Thus the effect of SHE ( $50 \mathrm{mg} / \mathrm{Kg}$ per mice) to 24 week old mice along with treadmilling exercise has been subjected to study. An increase in expression of AKT and mTOR is observed in the SHE administered exercise group when comparing the control, where SHE is not provided. It is earlier reported that increase in expression of AKT and mTOR after exercise results in enhanced myofibrillar protein synthesis along with muscle hypertrophy leading to increased muscle mass. Also the myogenic regulatory factors, $\mathrm{MyoD}$ and $\mathrm{MyoG}$ is found to be enhanced in the test group, where SHE administration along with aerobic treadmilling, than the control. Though there is no increase in the mitochondrial biogenesis, as there is no increase in the expression of mitochondrial biomarkers, AMPK- and Cytochrome C, yet the increase in expression of UCP3 accounts for the mitochondrial protection against the stress created during treadmilling onto the muscle fibres. Thus, SHE administration along with mild exercise in the old mice group results in better outcome, wherein muscle atrophy can be overcome thereby making it suitable as a protein supplement to old age people.

Thus, upon comparing the protein expression from the hind limb muscle tissue of the exercise and non-exercise with their corresponding subgroup of SHE administered test group and SHE non-administered control group, it is revealed that together with exercising, SHE protein supplementation is a promising agent for enhanced muscle protein synthesis thereby finding its way to be dietary food supplement for endurance trainers in muscle hypertrophy.

Acknowledgment This research was a part of the Project titled "Development of functional foods using the form hippocampus" (No. 20150343), funded by the Ministry of Oceans and Fisheries, Korea.

\section{References}

Bordbar S, Anwar F, Saari N (2011) High-Value Components and Bioactives from Sea Cucumbers for Functional Foods. Marine Drugs 9(10): 17611805

Borselli C, Storrie H, Benesch-Lee F, Shvartsman D, Cezar C, Lichtman JH, Vandenburgh H, J Mooney D (2010) Functional muscle regeneration with combined delivery of angiogenesis and myogenesis factors. PNAS 107(8): 3287-3292

Busiello RA, Savarese S, Lombardi A (2015) Mitochondrial uncoupling proteins and energy metabolism. Front Physiol 6: 36

Collu-Marchese M, Shuen M, Pauly M, Saleem A, Hood DA (2015) The regulation of mitochondrial transcription factor A (Tfam) expression during skeletal muscle cell differentiation. Bioscience Rep 35(3): 221

Eva Blomstrand, Jorgen Eliasson, Hakan KR, Karlsson, Rickard Kohnke (2006) Branched-Chain Amino Acids Activate Key Enzymes in Protein Synthesis after Physical Exercise. J Nutr 36(1): 269-273

Feixia Hou, Longlian Wen, Cheng Peng, Jinlin Guo (2016) Identification of marine traditional Chinese medicine dried sea horses in the traditional Chinese medicine market using DNA barcoding. Mitochondr DNA Part A. doi: 10.1080/24701394.2016.1248430

Fernandes T, Soci UPR, Melo SFS, Alves CR, Oliveira EM (2012) Skeletal Muscle-From Myogenesis to Clinical Relations. Dr.Julianna Cseri (Ed.) Signaling Pathways that medicate Skeletal Muscle Hypertrophy: Effects of Exercise Training, InTech. doi:10.5772/51087

Gao AW, Carles C, Houtkooper RH (2014) Mitochondrial Response to Nutrient Availability and Its Role in Metabolic Disease. EMBO Mol Med 6(5): 580-589

Giaever I, Keese CR (1984) Monitoring fibroblast behavior in tissue culture with an applied electric field. Proc Natl Acad Sci U S A 81:3761-3764

Guadalupe-Grau A, Fernandez-Elas VE, Ortega JF, Dela F, Helge JW, Mora Rodrguez R (2017) Effects of 6-month aerobic interval training on skeletal muscle metabolism in middle-aged metabolic syndrome patients. Scand J Med Sci Sports. doi: 10.1111/sms.12881

Holloszy JO (1967) Biochemical Adaptations in Muscle: Effects of exercise on mitochondrial oxygen uptake and respiratory enzyme activity in skeletal muscle. J Biol Chem 242(9): 2278-2282

Hou Y, Wu Z, Dai Z, Wang G, Wu G (2017) Protein hydrolysates in animal nutrition: Industrial production, bioactive peptides and functional significance. J Anim Sci Biotechno 8: 24

Imen Hamed, Fatih Ozogul, Yesim Ozogul, Joe MR (2015) Marine Bioactive Compounds and Their Health Benefits: A Review. Compr Rev Food Sci Food Saf 14: 446-465

Keller Karsten, Engelhardt Martin (2013) Strength and Muscle Mass Loss with Aging Process. Age and Strength Loss. Muscles, Ligaments Tendons J 3(4): 346-350

Kim YM, Jeon YJ, Huh JS, Kim SD, Park KK, Cho MJ (2016) Effects of enzymatic hydrolysate from sea horse Hippocampus abdominalis on testosterone secretion from TM3 Leydig cells and in male mice. Appl Biol Chem 59(6): 869-879

Lene Meinert, Eva Honnens de Lichtenberg Broge, Camilla Bejerholm, Kirsten Jensen (2016) Application of hydrolyzed proteins of animal origin in processed meat. Food Sci Nutr 4(2): 290-297

Manninen AH (2009) Protein hydrolysates in sports nutrition. Nutr Metab 6: 38 
McCarthy AL, O'Callaghan YC, O'Brien NM (2013) Protein Hydrolysates from Agricultural Crops-Bioactivity and Potential for Functional Food Development. 112-130

Miranda Nabben, Joris Hoeks (2008) Mitochondrial uncoupling protein 3 and its role in cardiac- and skeletal muscle metabolism. Physiol Behav 94(2): 259-269

Nalae Kang, Seo-Young Kim, Sum Rho, Ju-Young Ko, You-Jin Jeon (2017) Anti-fatigue activity of a mixture of sea horse (Hippocampus abdominalis) hydrolysate and red ginseng. Korean J Fish Aquat Sci 20: 3

Pacagnelli FL, Aguiar AF, Campos DH, Castan EP, de Souza RW, de Almeida FL, Carani F, Carvalho RF, Cicogna AC, Silva MD (2016) Training improves the oxidative phenotype of muscle during the transition from cardiac hypertrophy to heart failure without altering MyoD and Myogenin. 101(8): 1075-1085

Patrick Schrauwen, Joris Hoeks, Matthijs K.C Hesselink (2006) Lipidinduced cell stress and insulin resistance. Scand J Med Sci Sports 50(2): $62-67$

Paul D. Thompson, Gregory Panza, Amanda Zaleski, Beth Taylor (2016) Statin-Associated Side Effects. J Am Coll Cordiol 67(20): 2395-2410

Perera N, Godahewa G, Lee J (2016) Copper-zinc-superoxide dismutase (CuZnSOD), an antioxidant gene from sea horse (Hippocampus abdominalis); molecular cloning, sequence characterization, antioxidant activity and potential peroxidation function of its recombinant protein. Fish Shellfish Immunol 57: 386-399

Philips S (2011) The science of muscle hypertrophy: Making dietary protein count. P Nutr Soc 70(1): 100-103

Raja Ganesan, Nina Judith Hos, Saray Gutierrez, Julia Fische, Joanna Magdalena Stepek, Evmorphia Daglid, Martin Kronke, Nirmal Robinson (2017) Salmonella Typhimurium disrupts Sirt1/AMPK checkpoint control of mTOR to impair autophagy. PLoS Pathog 13(2)

Richter EA, Ruderman NB (2009) AMPK and the biochemistry of exercise: Implications for human health and disease. Biochem J 418(2): 261-275

Schoenfeld BJ, Aragon AA, Krieger JW (2013) The Effect of Protein Timing on Muscle Strength and Hypertrophy: A Meta-Analysis. J Int Soc Sports Nut 10(53)

Sculcek R, Bogaard HJ, van Nieuw Amerongen GP (2014) Electric cellsubstrate impedance sensing for the quantification of endothelial proliferation, barrier function and motility. J Vis Exp 85:e51300

Teng S, Stegner D, Chen Q, Hongu T, Hasegawa H, Chen L, Kanaho Y, Nieswandt B, Frohman MA, Huang P (2015) Phospholipase D1 facilitates second-phase myoblast fusion and skeletal muscle regeneration. Mol Biol Cell 26(3): 506-517

Terjung RL, Winder WW, Baldwin KM, Holloszy JO (1973) Effect of Exercise on the Turnover of Cytochrome $\mathrm{c}$ in Skeletal Muscle. J Biol Chem 248(21): 7404-7406

Valente LMP, Moutou KA, Conceicao LEC, Engrola S, Fernandes JMO, Johnston IA (2013) What determines growth potential and juvenile quality of farmed fish species?. Rev Aquacult 5: S168-S193

Vijaykrishnaraj M, Prabhasankar P (2015) Marine protein hydrolysates: their present and future perspectives in food chemistry. 34864-34877

Vincenzo Nobile, Elisa Duclos, Angela Michelotti, Gioia Bizzaro, Massimo Negro, Florian Soisson (2016) Supplementation with a fish protein hydrolysate (Micromesistius poutassou): effects on body weight, body composition, and CCK/GLP-1 secretion. Food Nutr Res 60: 29857

Wengong Wand, Xialing Yang, Isabel Lopez de Silanes, David Carling, Myriam Gorospe (2003) Increased AMP: ATP Ratio and AMP-activated Protein Kinase Activity during Cellular Senescence Linked to Reduced HuR Function. J Biol Chem 278: 27016 